\title{
Tecendo habilidades empáticas: uma experiência com crianças e adolescentes
}

\author{
Weaving empathic skills: an experience with children and adolescents
}

Tejiendo habilidades empáticas: una experiencia con niños y adolescentes

Mychelle Maria Santos de Oliveira ${ }^{1 *}$, Maria Camila da Silva ${ }^{1}$, Sara Raquel Araújo Costa ${ }^{1}$, Teresinha de Jesus Sousa Silva ${ }^{1}$, Maria do Perpétuo Socorro Gonçalves Andrade ${ }^{1}$, Pedro Wilson Ramos da Conceição ${ }^{1}$, Avelino Ribeiro de Castro ${ }^{1}$, Érika Castelo Branco Said ${ }^{1}$, Ana Valéria Lopes Lemos ${ }^{1}$, Izabel Cristina Vale de Carvalho ${ }^{1}$, Zaira Arthemisa Mesquita Araújo ${ }^{1}$, Francisca Tatiana Dourado Gonçalves ${ }^{1}$.

\section{RESUMO}

Objetivo: Relatar as experiências advindas da aplicação de um projeto de intervenção, realizado em um Centro da Juventude. Detalhamento do Caso: O projeto é resultado do Estágio Básico em Psicologia Social e Comunitária. As intervenções foram realizadas durante oito encontros, com o público infantil e juvenil do Centro da Juventude de um município do interior do Maranhão, durante o primeiro semestre de 2019. As atividades foram realizadas com aproximadamente trinta assistidos e os instrumentos foram selecionados para atuar em prol do coletivo. Para isso, utilizou-se as dinâmicas de grupo e os jogos cooperativos com a finalidade de estimular a empatia e promover o autoconhecimento e reconhecimento do próximo entre os assistidos desse equipamento. Considerações Finais: $O$ uso de atividades dinâmicas e cooperativas mostrou-se eficaz para o exercício da prática do respeito, escuta e de um novo olhar sobre o outro, logo, contribui com o fortalecimento de vínculo entre os assistidos e promove bem-estar.

Palavras-chave: Empatia, Criança, Adolescente.

\begin{abstract}
Objective: To report the experiences arising from the application of an intervention project carried out in a Youth Center. Case Detail: The project is the result of the Basic Internship in Social and Community Psychology. The interventions were carried out during eight meetings with the youth and children audience of the Youth Center of a municipality in the interior of Maranhão, during the first semester of 2019. The activities were carried out with approximately thirty assisted and the instruments were selected to act in favor of the collective. For this, we used the group dynamics and cooperative games in order to stimulate empathy and promote self-knowledge and recognition of others in the assisted of this equipment. Final Considerations: The use of dynamic and cooperative activities proved to be effective for the practice of respect, listening and a new look on the other, thus contributing to the strengthening of bond between the assisted and promotes well-being.
\end{abstract}

Key words: Empathy, Kid, Adolescent.

\section{RESUMEN}

Objetivo: Informar las experiencias derivadas de la aplicación de un proyecto de intervención llevado a cabo en un Centro Juvenil. Detalle del caso: El proyecto es el resultado de la pasantía básica en psicología social

${ }^{1}$ Centro Universitário de Ciências e Tecnologia do Maranhão (UniFacema), Caxias-Maranhão.

*E-mail: mychelles@outlook.com 
y comunitaria. Las intervenciones se llevaron a cabo durante ocho reuniones con niños y jóvenes del Centro Juvenil de un municipio en el interior de Maranhão, durante el primer semestre de 2019. Las actividades se llevaron a cabo con aproximadamente treinta asistentes y se seleccionaron los instrumentos para actuar a favor del colectivo. Para esto, utilizamos la dinámica de grupo y los juegos cooperativos para estimular la empatía y promover el autoconocimiento y el reconocimiento de los demás en la asistencia de este equipo. Consideraciones finales: El uso de actividades dinámicas y cooperativas demostró ser efectivo para la práctica del respeto, la escucha y una nueva mirada del otro, contribuyendo así al fortalecimiento del vínculo entre los asistidos y promueve el bienestar.

Palabras clave: Empatía, Niño, Adolescente.

\section{INTRODUÇÃO}

O ser humano é reflexo de uma interação biopsicossocial e as experiências adquiridas durante as fases iniciais do desenvolvimento são imprescindíveis para a maturação do indivíduo a nível físico, afetivo e psicossocial (PAPALIA DE e FELDMAN RD, 2013).

Notoriamente, o público infanto-juvenil é significativamente vulnerável a estimulação sensorial, uma vez que essas etapas apresentam teor dinâmico, de rupturas e aprendizagens constantes (ALVARENGA P, et al., 2016; SILVA VA e MATTOS HF, 2004).

A atual dinâmica social fornece modelos ambíguos de atitudes e comportamentos, pois ao mesmo tempo que oferece repertórios baseados na competição e orientados por objetivos individuais, o mercado de trabalho exige comportamentos flexíveis e adaptativos, uma vez que estão relacionados com a motivação, produtividade e com relacionamentos sociais saudáveis (COLOMBO G e PRATTI LE, 2014; PALMIERI MWA e BRANCO AU, 2004).

Paralelo a isso, a aquisição de um repertório comportamental adaptativo exige a consolidação de requisitos basais, como as habilidades interpessoais que são necessárias para o bom convívio social. Caso estas habilidades sejam deficitárias, pode haver uma instabilidade nas etapas posteriores, dificultando os relacionamentos sociais e interferindo na qualidade de vida do sujeito (DEL PRETTE ZAP e DEL PRETTE A, 2018),

A empatia é uma das habilidades necessárias para o estabelecimento de uma rede de vínculos saudável, pois essa competência social se refere a capacidade da pessoa se afetar e entender as emoções do outro (SOARES AMR e RIO OLIVEIRA CP, 2019).

A manifestação de comportamentos empáticos exerce influência direta com o desempenho acadêmico, com a responsabilidade, autonomia, autoconceito e relações interpessoais (DEL PRETTE A, et al., 2011).

Diante disso, o presente relato visa apresentar as experiências vivenciadas no Estágio Básico em Psicologia Social e Comunitária, desenvolvido no Centro da Juventude de um município do interior do Maranhão, na qual as atividades desenvolvidas foram pautadas com o propósito de estimular a empatia nos assistidos desse equipamento.

\section{DETALHAMENTO DO CASO}

O presente relato é resultado das vivências do Estágio Básico em Psicologia Social Comunitária, realizado semanalmente no Centro da Juventude de um município do interior do Maranhão, no turno matutino, durante os meses de fevereiro a maio de 2019.

O Centro da Juventude é um equipamento público da rede socioassistencial, cujo objetivo consiste em ofertar proteção e garantia dos direitos do público juvenil que se encontram em situação de vulnerabilidade. Esse equipamento busca fomentar a aprendizagem, senso crítico, valores sociais e protagonismo a fim de promover o bom convívio interpessoal (BRASIL, 2001). 
O projeto foi desenvolvido durante oito encontros com o público infanto-juvenil do referido equipamento. As intervenções foram realizadas com aproximadamente trinta assistidos e a elaboração da proposta de intervenção foi realizada em três etapas: contato com o público-alvo, mapeamento/análise das demandas emergentes do equipamento e a proposta de intervenção. A partir do contato direto com o grupo-alvo, observou-se a dificuldade dos assistidos em atuarem em uma relação grupal, diante disso, utilizou-se como instrumentos para a aplicação das intervenções, dinâmicas de grupo e jogos cooperativos com o objetivo de promover um espaço para a integração, estímulo da escuta, ajuda, altruísmo e autoestima.

No primeiro encontro, intitulado "Prazer em conhecer você!", foi desenvolvida uma dinâmica com o propósito de elaborar um espaço para o conhecimento do outro. Diante dessa atividade, os participantes demonstraram interesse, engajamento e respeitaram o discurso dos colegas. No segundo encontro, "Sentimento em balões", foi realizada a apresentação de sentimentos relacionados a empatia. Foi solicitado que os participantes formassem um círculo, e cada assistido voluntariamente refletia se um determinado sentimento era compatível ou não com o comportamento empático. A maior parcela do público-alvo participou ativamente da dinâmica, contudo um dos empecilhos foi o desconhecimento do significado de algumas palavras relacionados a empatia, o que inviabilizou a participação de alguns assistidos.

O terceiro encontro "Conhecendo o outro através das emoções", trabalhou sob a ótica de estimular a atenção, escuta, conhecimento dos sentimentos do próximo e o autoconhecimento. O procedimento consistia em expressar uma emoção de acordo com o ritmo de cada música, sendo estas no estilo pop, axé, forró, funk. Os participantes aderiram positivamente a atividade e respeitaram o espaço do próximo.

$\mathrm{Na}$ quarta intervenção, "Jardim das Emoções", o cerne da atividade consistiu em promover o resgate de eventos significativos na vida de cada participante. A atividade foi realizada com 20 assistidos e na execução do procedimento, cada assistido retirava um objeto de uma mala e fazia breves comentários sobre aquele material, enfatizando se estes tinham algum significado e se fazia ele lembrar de algum recorte de sua vida. Majoritariamente, os assistidos contribuíram com a execução da dinâmica, contudo muitos optaram por não relatarem suas lembranças.

No encontro seguinte, foi realizada uma "Gincana de Jogos Cooperativos". Foi aplicada uma adaptação da brincadeira cobra-cega, "Passando o bambolê" e o "Nó Humano", com a finalidade de estimular o contato físico e a capacidade para resolver problemas. A atividade foi bem recebida e os assistidos foram cooperativos, visto que auxiliaram os colegas na resolução das atividades.

No sexto encontro, foi realizado o "Semáforo das Emoções", cujo procedimento solicitava que os participantes confeccionassem um semáforo e escrevessem sobre atitudes e comportamentos que deveriam ser reduzidos, refletidos ou adicionados ao repertório de cada um. No curso da intervenção, os assistidos demonstraram empenho e mostraram-se criativos. Apesar de muitos escolherem não falar sobre suas experiências, a observação permitiu constatar que a grande parcela dos discursos estava relacionada a família, amigos e quando agiam de uma forma não assertiva, isso causava incômodo nos assistidos.

Na sétima intervenção, foi promovida a dinâmica da "Caixa Surpresa" a fim de instigar o reconhecimento das qualidades do outro e as próprias características. A caixa foi passada e repassada entre os assistidos com base nas características de cada um, características estas como gentileza, otimismo, simpatia etc. O último participante que recebeu o presente, foi orientado a compartilhá-lo com os demais. Apesar do reconhecimento das qualidades do próximo, alguns assistidos praticaram bullying verbal em relação as características físicas e sociais dos colegas.

O último encontro, nomeado de "Reflexão e Descontração" foi destinado ao encerramento do projeto, para isso, foi articulada uma roda de conversa para reflexão e recapitulação dos objetivos das intervenções, pontuando a importância da empatia nas relações sociais e no desenvolvimento de cada assistido, assim como, foi enfatizada a relevância da escuta, ajuda ao próximo, do senso crítico e do autoconhecimento. Em seguida, os assistidos dançaram e cantaram ao som de músicas escolhidas por eles, foi servido o lanche $e$ cessado a aplicação das intervenções. A atividade alcançou uma significativa participação das crianças e dos adolescentes, muitos se divertiram e brincaram com os colegas. 


\section{DISCUSSÃO}

Trabalhar com comunidades é um campo vasto, possibilita um leque de experiências e o desenvolvimento de várias intervenções que possam contemplar as demandas presentes nesse campo. As ações nas comunidades devem ser pautadas pelas necessidades e anseios do espaço, pela colaboração mútua e deve visar o desenvolvimento, qualidade de vida e bem-estar psicossocial dos atores ali presentes (MACIEL TMFB e ALVES MBA, 2015).

Os estímulos e variáveis sociais e ambientais aos quais os indivíduos estão expostos são contribuintes para a sua maturação orgânica, psicológica e social (SAKURAMOTO SM et al., 2014). Diante disso, a escolha das dinâmicas de grupo se deu por ser um recurso sócio pedagógico e lúdico terapêutico que age sob a perspectiva de estimular a socialização entre todos os membros do grupo (CUNHA LS et al., 2016).

Em relação aos jogos cooperativos, Silva Nunes G et al. (2017) destaca que essa ferramenta busca promover a solidariedade, reduzir comportamentos agressivos e individualistas por meio do trabalho em equipe. Ambas as ferramentas apresentam um teor motivador, instigante e atuam na perspectiva psicossocial sob a ótica de desenvolver o envolvimento grupal, a reflexão acerca de temas propostos, busca estimular a potencialidade dos membros, a criatividade, liderança, habilidades sociais e superar desafios (ALBERTI TF et al., 2014; LUIZ GM, et al., 2014). Mediante o pensamento de Krznaric R (2015), a manifestação de atitudes e comportamentos empáticos implicam transformações no cenário social. Essa competência é um fator de proteção pois colabora com a adaptação, abertura a experiências, manejo comportamental em situação de conflito, assim como, promove a resiliência, o desenvolvimento de valores éticos e morais e diminui a vulnerabilidade social (CECCONELLO AM e KOLLER SH, 2000; FORMIGA NS, 2013).

No curso dos encontros, as atividades ofertadas serviram como uma ferramenta para a promoção do reconhecimento da memória individual e grupal, que segundo Augustin RL e Augustin S (2012) é um elemento fundamental para o estímulo do protagonismo e da transformação do indivíduo em um sujeito histórico-social. Ainda mais, contribuiu com a cooperação e estímulo do protagonismo, figura disso foi a constatação de que alguns assistidos que não se manifestavam anteriormente, no decorrer das atividades e com o passar dos encontros, passaram a se expressarem, a articularem sobre suas vivências e sentimentos em relação as dinâmicas desenvolvidas.

O contato frente a frente entre os participantes viabilizou o conhecimento e reconhecimento do próximo, diante disso, convém destacar que as mudanças ocorrem em nível coletivo, onde as alterações em uma parte do grupo repercutem em outras, de forma a possibilitar a aquisição de novos caracteres a personalidade dos sujeitos, contribuindo com o desenvolvimento cognitivo, psicomotor e socio afetivo (ALBERTI TF, et al., 2014).

A escolha das intervenções foi orientada de modo a englobar as dificuldades holísticas desse cenário, de tal forma que foram planejadas detalhadamente com o objetivo de alcançar o máximo de respeito, integração e consciência grupal, visto que são requisitos que favorecem a empatia. Diante disso, Del Prette A e Del Prette ZAP (2001) afirmam que a empatia pode criar ou intensificar bons relacionamentos entre as pessoas, fortalecer vínculos de amizade, através da compreensão e da validação dos sentimentos do outro.

Em cada encontro, a ornamentação do espaço proporcionava curiosidade e atratividade dos assistidos e as atividades eram conduzidas de forma clara, simples e dinâmica sob uma perspectiva horizontal. Entretanto, as atividades foram marcadas por diversos imprevistos e empecilhos, exemplo disso foi a execução de dinâmicas simples que desencadeavam sentimentos diversos e mostravam-se complicadas para os assistidos; e, atividades que acreditávamos serem divertidas que para eles mostraram-se desagradáveis, monótonas e tediosas. Em vista disso, Wachelke JFR, et al. (2017) afirma que é necessário que as dinâmicas sejam adaptadas para o público, atendendo as necessidades de cada um com base nas suas particularidades.

Com o decorrer dos encontros, o público foi reduzido e a faixa etária entre os assistidos se aproximou, predominando o público infantil. Isso favoreceu a aplicação do projeto, uma vez que quando há uma discrepância na idade dos membros de um grupo, muitas vezes torna-se difícil o desenvolvimento de uma atividade que contemple as necessidades de cada um, pois a interpretação é resultado das experiências, idiossincrasias, contexto político, econômico e social de cada sujeito (SALLES LMF, 2005). 
Durante as intervenções, os assistidos mostraram-se participantes ativos desse processo, foram bem atenciosos, engajados, reflexivos, críticos e curiosos. Desse modo, os objetivos propostos foram alcançados e interpretados de forma diferente para cada participante, pois a subjetividade é um processo amplo e diverso (PEREIRA MS, et al., 2018). Esse projeto repercutiu efeitos em uma via dupla, pois contribuiu com a estimulação da empatia, cooperação, respeito, com a prática de um novo olhar sobre o outro e a autopercepção nos assistidos, além disso, as consequências desse projeto gerou reflexos no processo de aprendizagem, na atuação prática, no desenvolvimento da ética, respeito, compromisso e responsabilidade social das estagiárias.

\section{CONSIDERAÇÕES FINAIS}

A empatia é uma competência social que pode ser estimulada e potencializada em qualquer etapa da vida, considerando o contexto histórico, social e cultural do público-alvo. O uso de dinâmicas e jogos cooperativos são lúdicos recursos terapêuticos que atuam em prol da construção de um espaço que promova a cooperação, compreensão e escuta do outro. Diante disso, a elaboração das atividades estava voltada para viabilizar a integração grupal, por isso, em cada encontro, o espaço era organizado de maneira didática a fim de instigar a participação dos assistidos. No entanto, no curso das intervenções aconteceram eventualidades, nas quais o grupo-alvo demonstra desinteresse pelas dinâmicas, além disso, os recursos utilizados atuaram em uma outra vertente, pois estimularam a participação de assistidos mais tímidos, promovendo o senso reflexivo. Assim, a manifestação contínua das habilidades empáticas resulta na aprendizagem de comportamentos funcionais e adaptativos, o que por consequência promove o fortalecimento de vínculos interpessoais e o bem-estar psicossocial.

\section{REFERÊNCIAS}

1. ALBERTI TF, et al. Dinâmicas de grupo orientadas pelas atividades de estudo: desenvolvimento de habilidades e competências na educação profissional. Revista Brasileira de Estudos Pedagógicos, v. 95, n. 240, 2014.

2. ALVARENGA $P$, et al. Cuidados parentais e desenvolvimento socioemocional na infância e na adolescência: uma perspectiva analítica comportamental. Revista Brasileira de Terapia Comportamental e Cognitiva, v. 18, n. 1, 2016.

3. AUGUSTIN RL, AUGUSTIN S. Memória e suas implicações na vida cotidiana: análise teórica. Métis: história \& cultura, v. 11, n. 21, 2012.

4. BRASIL. Portaria MPAS/SEA № 879 de 3 de dezembro de 2001. Diário Oficial da República Federativa do Brasil, Brasília, DF, 19 de dezembro de 2001, Seção 1, p. 91.

5. CECCONELLO AM, KOLLER, SH. Competência social e empatia: um estudo sobre resiliência com crianças em situação de pobreza. Estudos de psicologia (Natal). Vol. 5, n. 1 (jan./jun. 2000), p. 71-93, 2000.

6. COLOMBO G, PRATI LE. Maturidade para escolha profissional, habilidades sociais e inserção no mercado de trabalho. Revista Brasileira de Orientação Profissional, v. 15, n. 2, p. 201-212, 2014.

7. CUNHA LS, et al. Um estudo sobre a importância da dinâmica de grupo no processo de aprendizagem de professores. Faculdade Promove de Brasília, 2016.

8. DEL PRETTE, A, DEL PRETTE ZAP. (2001). Habilidades sociais: Biologia evolucionária, sociedade e cultura. In: Guihardi, H. J, Madi, M. B. B. P., Queiroz, P. P., \& Scoz, M.C. (Orgs.), Sobre comportamento e cognição: Expondo a variabilidade (pp.65-75). Santo André: ESETec.

9. DEL PRETTE A, et al. Habilidades Sociais na comorbidade entre dificuldades de aprendizagem e problemas de comportamento: uma avaliação multimodal. Porto Alegre: PUCRS, 2011.

10. DEL PRETTE ZAP, DEL PRETTE A. Competência social e habilidades sociais: manual teórico-prático. Petrópolis, RJ: Editora Vozes Limitada, 2018.

11. FORMIGA NS. Os jovens e o reconhecimento da empatia: análise descritiva da reatividade interpessoal em jovens de diferentes contextos sociais. Revista de Psicologia, v. 4, n. 1, p. 75-82, 2013.

12. KRZNARIC R. O poder da empatia: a arte de se colocar no lugar do outro para transformar o mundo; trad.: Maria Luiza X. de A. Borges. - 1.ed. - Rio de Janeiro: Zahar, 2015.

13. LUIZ GM, et al. Intervenção psicossocial por meio de oficina de dinâmica de grupo em uma instituição: relato de experiência. Psicologia Revista, v. 23, n. 2, p. 245-260, 2014.

14. MACIEL TMFB, ALVES MB. A importância da psicologia social comunitária para o desenvolvimento sustentável. Pesqui. prát. psicossociais, São João del-Rei , v. 10, n. 2, p. 272-282, dez. 2015. 
15. PALMIERI MWA, BRANCO AU. Cooperação, competição e individualismo em uma perspectiva sócio-cultural construtivista. Psicologia: reflexão e crítica, v. 17, n. 2, p. 189- 198, 2004.

16. PAPALIA, DE, FELDMAN RD. Desenvolvimento humano. Porto Alegre: Artmed Editora, 2013.

17. PEREIRA MS, et al. Estágio Profissionalizante e Formação em Psicologia: o Trabalho com Grupos como Dispositivo Formativo. Psicol. cienc. prof., Brasília, v. 38, n. 2, p. 218-232, June 2018.

18. SAKURAMOTO SM, et al. Apoio social, estilo parental e a saúde mental de crianças e adolescentes. Mundo Saúde (Impr.), v. 38, n. 2, p. 169-78, 2014.

19. SALLES LMF. Infância e adolescência na sociedade contemporânea: alguns apontamentos. Estud. psicol. (Campinas), Campinas, v. 22, n. 1, p. 33-41, Mar. 2005.

20. SILVA NUNES G, et al. Jogos cooperativos como ferramenta para diminuir o nível de competitividade entre equipes. Mostra Científica de Educação Física, v. 1, n. 2, 2017.

21. SILVA VA, MATTOS HF. Os jovens são mais vulneráveis as drogas?. In: Em Pinsky, I.; Bessa, M. A. (Eds.). Adolescência e drogas. São Paulo: Contexto, 2004.

22. SOARES AMR, RIO OLIVEIRA CP. Neurônios espelhos na aprendizagem social e comportamental na educação infantil: uma análise transdisciplinar da imitação e da empatia sob a perspectiva neurocientífica. Paidéia, v. 13, n. 20, p. 89-107, 2019.

23. WACHELKE JFR, et al. Construção e utilização de técnicas em dinâmica de grupos. Psicologia Argumento, v. 23, n. 42, p. 31-39, 2017. 